\title{
Modeling the Impacts of Local Factors for Healthcare Building Energy Performance Improvement in Thailand
}

\author{
Nuttasit Somboonwit, Nopadon Sahachaisaeree \\ Multidisciplinary Design Research, Faculty of Architecture, \\ King Mongkut's Institute of Technology Ladkrabang, Chalongkrung Road, Ladkrabang, Bangkok, 10520, Thailand \\ nuttasit.somboonwit@gmail.com.
}

\begin{abstract}
This research aims to perform, compare, and evaluate Integrated Building Design (IBD) processes, collaborating the Building Information Modeling (BIM) with Building Performance Simulation (BPS) applications to perform energy analysis and to improve the building energy performance of a Generalizable Building Design (GBD), an universal application on health care facilities design in Thailand. The IBD processes produce the simulation results in a harmonious direction. Slight variation of building orientation could alter the extent of energy consumption. The integration of the three measures could minimize the energy consumption greatly. The study addresses limitations of the IBDs in the software integration processes.
\end{abstract}

Keywords: Local Factors in Construction ; Energy Performance Improvement ; Generalizable Healthcare Building Design ; Integrated Building Design.

eISSN 2514-751X @ 2018. The Authors. Published for AMER ABRA cE-Bs by e-International Publishing House, Ltd., UK. This is an open-access article under the CC BY-NC-ND license (http://creativecommons.org/licenses/bync-nd/4.0/). Peer-review under responsibility of AMER (Association of Malaysian Environment-Behaviour Researchers), ABRA (Association of Behavioural Researchers on Asians) and cE-Bs (Centre for EnvironmentBehaviour Studies), Faculty of Architecture, Planning \& Surveying, Universiti Teknologi MARA, Malaysia. https://doi.org/10.21834/aje-bs.v3i8.288 


\subsection{Introduction}

The Design and Construction Division (DCD) is a government agency in the management and administration of government health care facility buildings design and construction in Thailand.

Thailand public health care facilities have been classified into four levels; primary, secondary, tertiary, and excellent centers. Most of them are small to medium hospitals and local medical centers serving impoverished population in the rural areas. Totally, there are 781 government's Secondary Level hospitals which 200 of them are the Intermediate Secondary (2.2 Level) Health Care Facilities providing medical care and social services for more than 20 millions of Thai people.

\subsection{DCD's Generalizable Building Designs}

The majority of these 2.2 Level Health Care Facilities has been designed under the DCD's Generalizable Building Designs (GBDs), general ideas derived from the one-size-fits-all design concept for practical application on health care facilities design which are in the GBD criteria of its utilization; types, functions, sizes and work load capacities, for the sake of time and resources minimization during new building design processes. Those GBDs are intended for being constructed in rural areas all over the country and should be simple and easy to build by any local contractors which most of them are using low technology, inexpensive materials. There are more than 500 of them that still being effectively exploited and provided from the $D C D$ to be included in nearly all of the construction project delivery packages for primary and secondary level health care facilities.

Though, GBDs have been applied lacking decisive thoughtfulness on the local factors; i.e., location, orientation, and weather condition, and particularly, inept configuration of the site planning to minimize energy consumption. Besides, seemingly every $\mathrm{DCD}$ architects have limited knowledge on building energy performance; yet depend much upon their experiences and intuition during the design process.

\subsection{Building Information Modeling and Integrated Building Design Process}

The DCD has sought for new ways of working and alternative tools supplanting the oldfashioned 2D CAD and error-prone paper-based modes of communication (Eastman et al., 2008). A promising tool has been Building Information Modeling (BIM). The BIM is an emerging tool / methodology / process of virtual design and construction which creates and uses the coordinated, consistent, computable information of the 3D models of the project components interconnect with the holistic information with the project's planning, construction, operation, and decommissioning (Krygiel and Nies, 2008; Kymmell, 2008).

Perceiving a lot of benefits of BIM and its distinguished abilities through several pilot implementations, BIM has shown a lot of promise to succeed 2D CAD for DCD officers. To achieve the BIM's greatest productivity benefit, DCD architects have attempted to utilize it in multidisciplinary collaboration, with the software integration which the goal is to obtain high performance building designs during the early phase of design processes.

This study aims to perform, compare, and evaluate the data integration of Integrated 
Building Design (IBD) processes, design processes in which multiple disciplines and seemingly unrelated aspects of design and a range of simulation tools are integrated in a manner that permits synergistic benefits to be realized (U.S. Department of Energy, 2001; Treldal, 2008), collaborating the BIM with the Building Performance Simulation tool (BPS) to perform energy analysis, and improving the building energy performance of the case study building to state the recommendations and guidelines of the BIM-BPS integration in Generalizable Building Design (GBD) process for DCD architects.

\subsection{Methodology}

\subsection{BIM and BPS tools selection}

The Revit Architecture software is utilized for the BIM application, and for the BPS applications, the Ecotect Analysis and DesignBuilder are selected to perform energy analysis. Revit Architecture is a BIM software developed by Autodesk, Inc., Ecotect Analysis is an environmental analysis tool with highly graphical interface that allows designers to simulate building performance from the earliest stages of conceptual design (Wikipedia, 2010; Krygiel and Nies, 2008). Ecotect uses the CIBSE Admittance Method to calculate heating and cooling loads for models. On the other hand, DesignBuilder is a fully featured EnergyPlus user interface software tool for creating and assessing building designs. EnergyPlus is a considered highly accurate building performance simulation engine and it has been widely reviewed and validated using the ASHRAE/BESTEST evaluation protocol (Attia and De Herde, 2011). A distinguish capability of BIM is inter-transferring of the building geometry and embedded information from the model with other applications to retain the consistency of data and eliminates the need to replicate data input that has already been generated thus a considerable amount of modeling time can be reduced. The Green Building $\mathrm{XML}$ schema (gbXML), a schema developed to transfer energy consumption characteristics of buildings and information needed for preliminary energy analysis that usable by many BES applications currently available on the market (Eastman et al., 2007; Krygiel and Nies, 2008), is employed for data transfer in the BIM-BES integration.

\subsection{Local factors}

The location to simulate the building energy performance of the case study building is Bangkok, Thailand. Its global coordinates are $13^{\circ} \mathrm{N} 100^{\circ} 30^{\prime} \mathrm{E}$. Bangkok lies two meters above sea level and it has a tropical wet and dry climate, the annual temperature mean value is $27.83 \mathrm{OC}$ and high temperature mean daily value is $32.73 \mathrm{OC}$ (World Climate, 2011). The calculation of thermal properties of the local construction materials is following the Ministry of Energy's notification on Criteria and Calculation Methods for Building Design of Various Systems, Overall Energy Consumption of Buildings and Use of Renewable Energy of Various Building Systems B.E. 2552, Thailand (DEDE, 2009). 


\subsection{Case study building selection and descriptions}

The DCD's Generalizable Building Design number 10404 is chosen as a case study. Figure 1 (a) shows the floor plan of the case study building, it is a small single storey building consists of $557 \mathrm{~m} 2$ functional area used for Emergency Medicine Services.

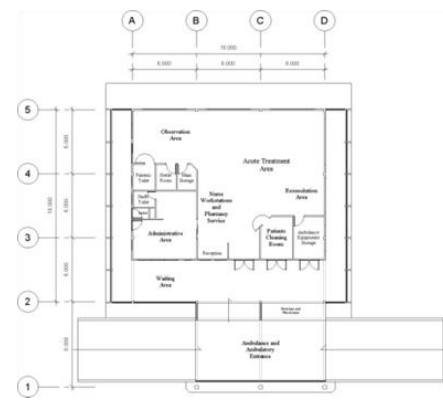

(a)

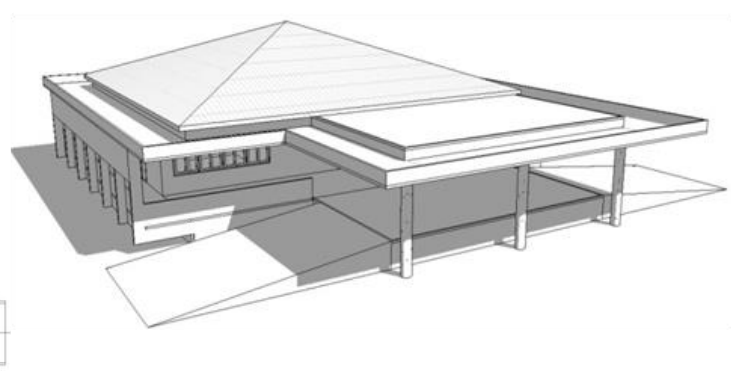

(b)

Figure 1: (a) The case study building floor plan; (b) a south-southwest perspective of the baseline model

Its physical characteristics are those of typical budget controlled government's health facility buildings.

Table 1. U Values of the Case Study building components

\begin{tabular}{lll}
\hline Component & U Value $(W / m-K)$ & Solar Absorption \\
\hline $100 \mathrm{~mm}$ Plastered Brick Wall & 3.19 & 0.5 \\
$100 \mathrm{~mm}$ Concrete Wall & 4.04 & 0.5 \\
$100 \mathrm{~mm}$ Concrete Floor & 4.04 & 0.7 \\
$100 \mathrm{~mm}$ Concrete Slab Roof & 4.04 & 0.7 \\
$100 \mathrm{~mm}$ Concrete Floor Ceramic Tile & 3.78 & 0.7 \\
Sloping Roof & 2.79 & 0.7 \\
$6 \mathrm{~mm}$ Single Clear Glazing Window & 5.62 & SHGC 0.73 \\
$10 \mathrm{~mm}$ Gypsum Plaster Board Ceiling & 4.68 & - \\
\hline
\end{tabular}

Table 1 shows the $U$ values of the case study building's components. The floor-to-ceiling height of all interior spaces is $3.45 \mathrm{~m}$, and above them is the space under the roof, which has no natural ventilation by its design. The building has no specified building orientation at the first place; it will be determined whenever the construction project delivery packages provided form the DCD.

\subsection{Thermal zones and HVAC}

The case study building divided into three types of zones: air-conditioned thermal zones, natural ventilation thermal zones, and non-thermal zone. This building is located in a very hot and humid area; almost half of the building's area served by three cooling systems, no 
heating needed.

\subsection{Using BIM for energy analysis}

\subsection{Baseline model development}

To create the baseline information model, all the building components of the case study building specifications must be translated into the BIM's terms; the Revit Elements. Revit Architecture classifies elements by categories, families, and types. A category is a group of elements that utilized to model or document building design and families are classes of element in a category. A family is a group of elements with a common set of parameters, identical use, and similar graphical representation (Autodesk, 2010). Use system families to build the baseline model, system families are the predefined set of families.

There are limitations of practical BIM workflow for integration with the BES workflow because many BIM elements do not support information exchange identifying the thermal performance characteristics needed for energy analysis. These limitations causing a specific BIM workflow for energy performance analysis is a requisite.

It is important to simplify the baseline model to the necessary details to reduce energy simulation time. In this study, the Room-Based Modeling, the concept of modeling and defining each Room as its own thermal zone (Integrated Environmental Solutions, 2009) has been used to model and define rooms within the baseline model. Orient the main / ambulance and ambulatory entrances of the baseline model to the true south.

There are several settings more within the BIM, before exporting the energy model. The project information and room elements must be created and defined correctly, each room needs to be bound by a wall, floor, or roof (Krygiel et. al., 2010) and each area within the baseline model that will be affected by the mechanical system will need to have a room element added to it.

Arrange the Room Tags on each room elements, a room tag is an annotation element that added in the baseline model to display values for related parameters, and to identify and retain the consistency of the thermal zone names exporting to the BES program. Figure 1(b) shows a perspective view of the simplified case study building: the baseline model.

\subsection{Exporting to gbXML}

Examine the Rooms and Analytical Surface. Figure 2(a) shows the Export gbXML window. Export the Baseline model gbXML. If any incorrect surfaces are identified, the exporting process must be aborted. Ensure the gbXML is free from any warnings before completing the export.

\subsection{BIM-BPS integration of the baseline model}

Before importing the gbXML file of the baseline model for energy analysis, creating the materials libraries of Thailand's code-compliant for local construction material properties are necessary. Figure 3(b) shows a perspective of the baseline energy model. 


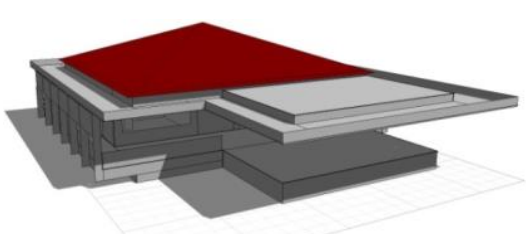

(a)

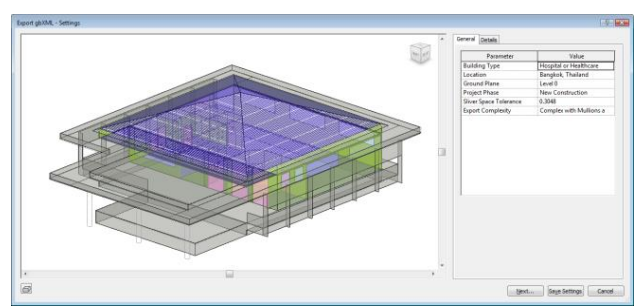

(b)

Figure 2 : (a) export gbXML - Setting Window; (b) a perspective of the baseline model energy model in Ecotect

Assign each zone properties using internal gains, infiltration rate, occupancy, and HVAC data. Apply weather data of Bangkok, Thailand as contextual information in the simulation processes. Set the orientation of the baseline energy model facing south; true north-based azimuth (AZI) of 180 , the $0 \square$ orientation. Simultaneously analyze the energy performance of the baseline orientation against seven types of geographic directions counterclockwise (CCW) as shown in Figure 3, to compare the differentiation of energy performance among directions.
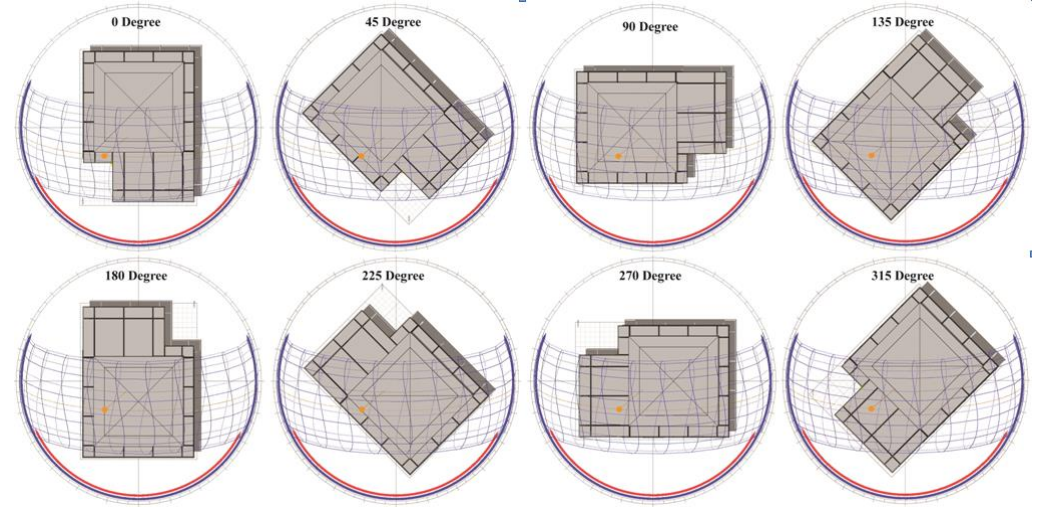

Figure 3: Counterclockwise rotations of the baseline model orientations

\subsection{Modification models}

An additional two types of modifications are performed to test the improvement of energy performance. Both of the modifications are simple and easy to build, using local building materials and construction techniques.

- Modification model 1: Model 1

The Model 1 replaces the envelope components of the baseline models with higher 
performance materials while the original building structure is retained. There are replacements of four building elements; improves the performance of solar absorption properties of the walls, roof slabs, and sloping roof. Reduce the solar absorption coefficient of concrete slabs and asbestos cement sheets roofing to 0.3 . Achieve an improvement of the glazing performance, the U-value has a reduction to $2.71 \mathrm{~W} / \mathrm{m} 2-\mathrm{k}$ and reduce SHGC to 0.44 . The $\mathrm{U}$-value of the roofs can be reduced to 0.30 . Furthermore, reduce the $\mathrm{U}$-value of the ceiling to 0.37 . Perform the Model 1 energy performance simulation against seven orientations in the similar way of the baseline model.

\section{- Modification model 2: Model 2}

The Model 2 has the equivalent properties of the replaced building elements to the Model 1 . Figure 4(a) shows a perspective rendering of Model 2 that the form of the roof has an alteration, from the square pyramid roof with horizontal concrete slab roof to a combined hip roof while its covering area is unchanged.

Improve the performance by uplifting of roof structure to allow better ventilation through the roof air pocket. Light shelves design is also added to minimize needs of artificial lighting during daytime as shown in Figure 4(b). There's a development of the Model 2 in the BIM system and a reprocess of BIM-BPS integration. Once again, the simulation settings and input data have been used to perform the energy performance simulation of model 2 and the

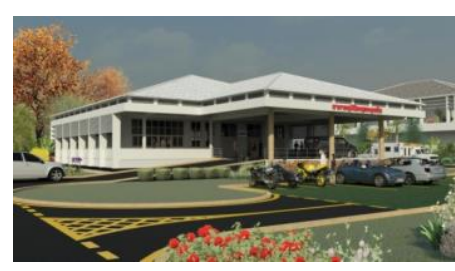

(a) other seven orientations as well.

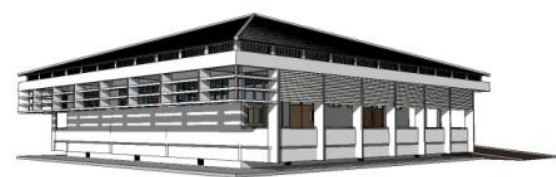

(b)

Fig. 4. (a) A perspective rendering of Model (b) a perspective view of Model 2 shows the light shelves

\subsection{Results and Discussion}

Simulated energy performances of all the three models are compared by means of energy consumption on monthly and annual cooling loads (Watt-hour: Wh).

\subsection{Energy performance of the baseline model}

Figure 5 depicts that the two IBD processes have produced the simulation results in a harmonious direction. The baseline model at the 0[orientation, the average simulated results from Ecotect of energy consumption on annual cooling loads is higher than DesignBuilder's results for $16.51 \%$ (6.90\% - 31.58\%). $11.37 \%$ and $9.09 \%$ for Model 1 and Model 2 respectively. 


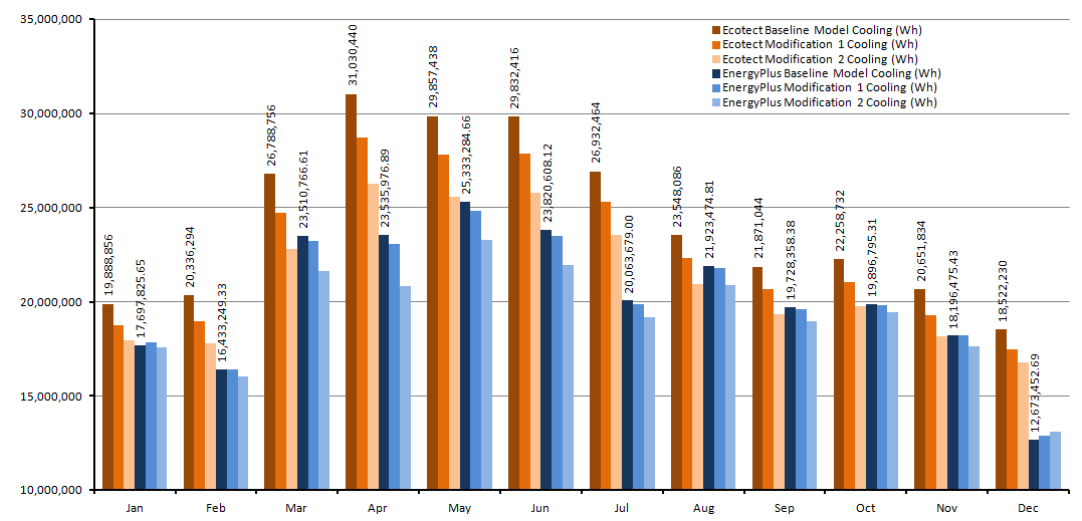

Fig. 5. Monthly energy consumption comparison of all models, the $0 \square$ orientation

\subsection{A comparison of results}

Figure 6 presents the best orientation for placing the baseline model is the 0lorientation and the worst one is the 270 Dorientation of both IBD processes, even though slightly variant (Ecotect: $0.051 \%$ - 0.455\%; DesignBuider: $0.07 \%$ - 0.55\%). It can be seen clearly that the baseline model at the 0lorientation is positioned by the narrowest and most shadowed side facing south. On the other hand, the 270-orientation places the baseline model's longest side to the south.

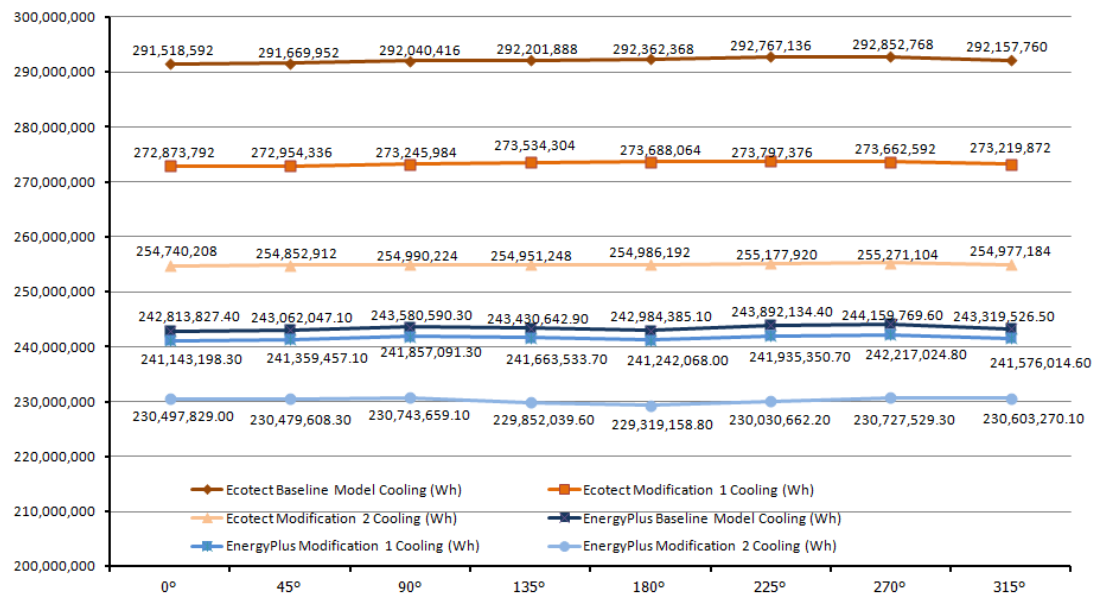

Fig. 6. Annual energy consumption comparison of all models against other seven orientations 
All models are single storey buildings; solar radiation through the roof originates the heat flows into the thermal zones that conduce to the largest amount energy consumption on cooling loads. And they are efficiently shaded by their architectural design, and therefore they have a good control of the direct solar gains, the cooling load remains almost the same while rotating the building in the different orientation angles.

Figure 7 shows the modification Model 1 that constitutes of high performance envelope materials shows its significant role on energy performance improvement, $6.39 \%-6.55 \%$ for Ecotect, and $0.69 \%-0.80 \%$ for DesignBuilder, of energy consumption can be reduced from the baseline model. The integration of three modification measures in Model 2 is the largest reduction of energy usage could minimize energy consumption as much as $12.62-12.84 \%$ for Ecotect, and 5.07\% - 5.68\% for DesignBuilder.

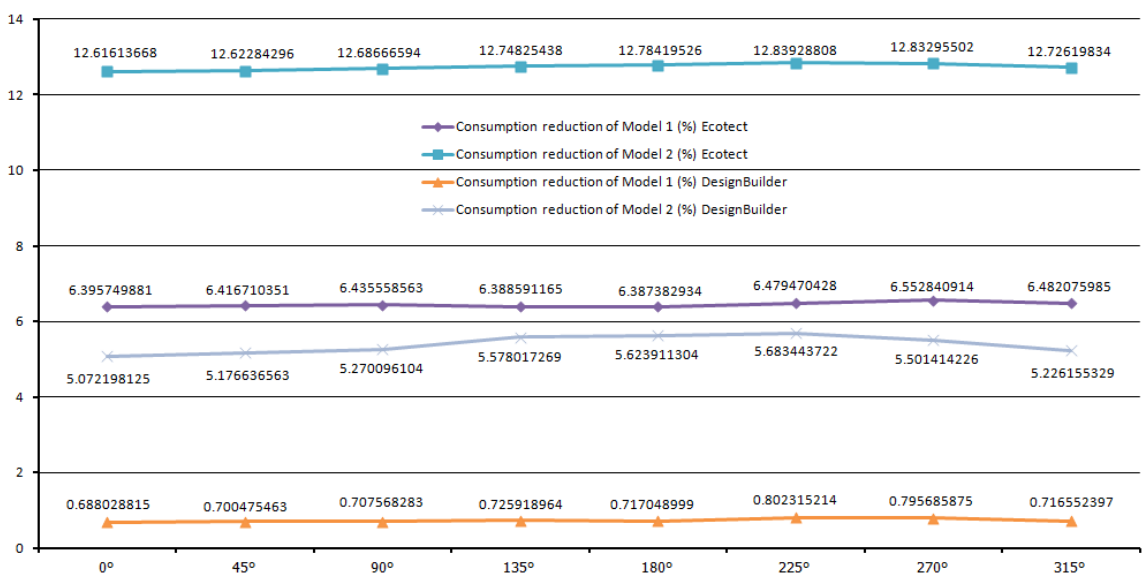

Figure 7: the percentage of annual energy consumption reduction compares to the baseline model

\subsection{Conclusion}

The expected outcome of this study is the perceiving of the DCD architects and engineers in Integrated Building Design processes (IBD). A study on BIM-BPS integration workflow of the case study building, an example of a small single storey Generalizable Building Design $(G B D)$ is a pilot experiment that's fundamental and encouraging the upcoming implementation of the IBD workflows for larger scale DCD's building designs and construction. Finding recommendations for the usage of the GBD on the impacts of building orientations, high performance building materials and passive cooling on building energy consumption may suggest some supportive information for more efficient construction in the future.

Comparison of the result of the BPS software, Ecotect and DesignBuilder, indicates significant disagreements because the dissimilar simulation methods of building performance 


\section{calculations.}

Finally, in order to take advantage of the capability to integrate BIM and BPS between the platforms, a fully integrated approach: workflows, tools, and, modeling and transferring standards will maximize the ability of the IBD - a crucial strategy for making buildings more sustainable in the future.

\section{References}

Autodesk. (2010). Revit Architecture 2011 User's Guide. Available from http://images.autodesk.com/adsk/files/revit_architecture_2011_user_guide_en.pdf

Attia, S. G., \& De Herde, A. (2011). Early Design Simulation Tools for Net Zero Energy Buildings: A Comparison of Ten Tools. Paper presented at the 12th Conference of International Building Performance Simulation Association, Building Simulation 2011, Sydney, Australia.

Department of Alternative Energy Development and Efficiency. (2009). Ministry of Energy's notification on Criteria and Calculation Methods for Building Design of Various Systems, Overall Energy Consumption of Buildings and Use of Renewable Energy of Various Building Systems B.E. 2552. Available from http://www2.dede.go.th/km_berc/downloads/

Eastman, C., Teicholz, P., Sacks, R., and Liston, K. (2008). BIM Handbook: A guide to Building Information Modeling for owners, managers, designers, engineers, and contractors. New Jersey: John Wiley \& Sons, Inc.

Energy Efficiency and Renewable Energy, U.S. Department of Energy. (2011). Weather Data. Available from http://apps1.eere.energy.gov/buildings/energyplus/weatherdata_format.cfm

Integrated Environmental Solutions. (2009). BIM + Building Performance Analysis Using Revit 2010 and IES < Virtual Environment>. Available from http://www.iesve.com.

Krygiel, E., and Nies, B. (2008). Green BIM: Successful Sustainable Design with Building Information Modeling. Indianapolis: Wiley Publishing, Inc.

Krygiel, E., Read, P., and Vandezande, J. (2010). Mastering Autodesk Revit Architecture 2011. Indianapolis: Wiley Publishing, Inc.

Treldal, N. (2008). Integrated Data and Process Control During BIM Design. Available from http://www.coinsweb.nl/downloads.

U.S. Department of Energy. (2001). Greening Federal Facilities: an energy, enivironmental, and economic resource guide for federal facility managers and designers. Available from http://www1.eere.energy.gov/.

World Climate. (2011). Bangkok, Thailand:Climate, Global Warming, and Daylight Charts and Data. Available from http://www.climate-charts.com/Countries/Thailand.html 